rev.relac.int.estrateg.segur.13(1)239-268,2018

\title{
La emergencia y aumento del antisemitismo en los gobiernos de Hugo Chávez y su relación con la profundización de las relaciones entre Venezuela e Irán (2005-2013)*
}

\author{
Margarita Figueroa Sepúlveda**
}

\section{Resumen}

A partir de 2004 Venezuela experimenta la emergencia de incidentes antisemitas que iniciaron con el hostigamiento a instituciones y personas de la comunidad judía del país, primero por parte de medios de comunicación y luego del Gobierno de Hugo Chávez. Esta situación se vio fortalecida por la profundización de relaciones con la República Islámica de Irán en 2005, bajo el Gobierno de Mahmud Ahmadineyad. El siguiente artículo analiza la relación entre la emergencia y el aumento del antisemitismo durante los últimos dos mandatos de Hugo Chávez y la profundización de las relaciones entre Venezuela e

\footnotetext{
El presente artículo se encuentra inscrito en el proyecto FONDECYT $\mathrm{N}^{\circ} 1150057$ titulado Antisemitismo e islamofobia como formas de intolerancia religiosa y cultural en las primeras décadas del siglo XXI. Los casos de Argentina y Chile del investigador Isaac Caro G.

** Cientista Político con especialización en Relaciones Internacionales, Universidad Alberto Hurtado. Coordinadora ejecutiva del Programa Interdisciplinario de Relaciones Internacionales para América Latina (Proial), del Departamento de Ciencia Política y Relaciones Internacionales, Universidad Alberto Hurtado. Correo electrónico: margaritafigueroa.sep@gmail.com
} 
Irán en el periodo 2005-2013. El objetivo es demostrar cómo la convergencia ideológica -sustentada en el antiimperialismo- entre los Gobiernos de Chávez y Ahmadinejad explica el desarrollo y aumento del antisemitismo en el Gobierno de Hugo Chávez. Para establecer la relación causal entre los fenómenos, se utilizó una metodología de análisis de seguimiento de procesos, con base en la evidencia empírica proporcionada por fuentes primarias y secundarias. Por consiguiente, se concluye que el antiimperialismo hizo que Israel fuera concebido como enemigo de ambos países, debido a su histórica alianza con Estados Unidos. Esto generó un anti-sionismo en Chávez, su gobierno y simpatizantes del mismo, que llevó a culpar a la comunidad judía venezolana por las acciones de Israel en Medio Oriente, y quienes posteriormente incurrieron en acciones y actitudes antisemitas, pasando desde el hostigamiento a la violencia física hacia personas de la comunidad judía del país.

Palabras clave: antisemitismo; antisionismo; antiimperialismo; conflicto palestino-israelí; ideología.

\section{The emergence and increase of anti-semitism in the governments of Hugo Chávez and its relationship with the deepening of the relations between Venezuela and Iran (2005-2013)}

\section{Abstract}

From 2004 Venezuela experiences the emergence of anti-Semitic incidents, that began with the harassment of institutions and people of the Jewish community of the country, first by the media and then by the government of Hugo Chavez. This situation was strengthened by deepening relations with the Islamic Republic of Iran in 2005 under the government of Mahmoud Ahmadinejad. The following article analyzes the relationship between the rise and increase of anti-Semitism during the last two terms of Hugo Chávez and the deepening of relations between Venezuela and Iran in the period 2005-2013. The aim is to demonstrate how the ideological convergence -supported in anti-imperialism- between the governments of Chavez and Ahmadinejad explains the development and increment of anti-Semitism in the government of Hugo Chavez. To establish the causal relationship between the phenomena, we used a methodology of processtracing analysis, based on the empirical evidence provided by primary and secondary sources. Therefore, it is concluded that anti-imperialism caused Israel to be conceived as an enemy of both countries, owing to its historic alliance with the United States. This generated anti-Zionism in Chávez, his government and supporters of it, which led to blaming the Venezuelan Jewish community for the ac- 
tions of Israel in the Middle East, which subsequently incurred anti-Semitic actions and attitudes, from harassment to physical violence against people in country's Jewish community

Keywords: anti-semitism; anti-zionism; anti-imperialism; palestinian-israeli conflict; ideology.

\section{O surgimento e aumento do anti-semitismo nos governos de Hugo Chávez e seu relacionamento com o aprofundamento das relações entre a Venezuela e o Irã (2005-2013)}

\section{Resumo}

De 2004 a Venezuela experimentou o surgimento de incidentes anti-semitas, que começou com o assédio de instituições e pessoas da comunidade judaica no país, primeiro pela mídia e, em seguida, pelo governo de Hugo Chávez. Esta situação foi reforçada com o aprofundamento das relações com a República Islâmica do Irã em 2005, sob o governo de Mahmud Ahmadineyad. O seguinte artigo discute a relação entre a emergência e ascensão do anti-semitismo durante os dois últimos termos de Hugo Chávez e o aprofundamento das relações entre a Venezuela e o Irã no período 2005-2013. O objetivo é demonstrar como a convergência ideológica -sustained em anti-imperialismo- entre os governos de Chávez e Ahmadinejad explica o desenvolvimento e aumento do anti-semitismo no governo de Hugo Chávez. Para estabelecer a relação causal entre os eventos, foi utilizado um monitoramento do processo de metodologia de análise, com base em evidências empíricas fornecidas por fontes primárias e secundárias. Portanto, concluímos que o anti-imperialismo causou Israel foi concebido como um inimigo de ambos os países, por causa de sua aliança histórica com os Estados Unidos. Isso gerou um anti-sionismo em Chávez, seu governo e apoiantes do mesmo, o que levou a culpa da comunidade judaica venezuelana para as ações de Israel no Oriente Médio, e que age posteriormente cometidos e atitudes anti-semitas, passando de assédio a violência física contra as pessoas da comunidade judaica no país.

Palavras-chave: anti-semitismo; anti-sionismo; anti-imperialismo; o conflito israel-palestiniano; ideologia. 


\section{Introducción}

Los altos índices de antisemitismo en la región (sobre el 30\%) tienen como uno de sus factores el conflicto en Medio Oriente, en específico el palestino-israelí, y el apoyo que los países de América Latina -y en especial Sudamérica- han dado a los países árabes y a Palestina los últimos 17 años (Anti-Defamation League [ADL], 2014; Siegel, 2011). Esta postura propalestina y actitud crítica respecto al actuar de Estados Unidos e Israel en Medio Oriente fue fortalecida por varios acontecimientos: la Segunda Intifada (2000), la invasión a Afganistán (2001), la guerra de Irak (2003) y el conflicto en la Franja de Gaza (a partir de 2009), los cuales significaron el rechazo de algunos países latinoamericanos a las acciones estadounidenses e israelíes en la región. Desde este contexto, al inicio de la guerra de Líbano de 2006 y de la Franja de Gaza de 2009, la cantidad e intensidad de la retórica antiestadounidense y antisionista aumentó significativamente (Siegel, 2011).

El apoyo de los países sudamericanos a Palestina y países árabes se debió, en parte, al ascenso de diferentes Gobiernos de izquierda a partir de 2000 en la región, quienes -a pesar de sus matices ideológicos- compartían entre sí visiones y principios sobre el orden internacional, por ejemplo, el establecimiento de un orden internacional multipolar, más equitativo y no hegemonizado bajo ninguna potencia (Moya, 2011). Igualmente, la paulatina retirada de Estados Unidos de la región como consecuencia de los atentados de 2001 y la orientación de su política exterior hacia Medio Oriente permitieron a los países llevar a cabo una diversificación de sus relaciones con el fin de contribuir a la construcción de este nuevo orden multipolar (Russell y Tokatlian, 2009). De esta forma, Medio Oriente, en su mayoría subdesarrollado y dependiente de la exportación de materias primas al igual que Sudamérica, se constituyó como un espacio de convergencia respecto a estos nuevos principios del orden internacional, como el antiimperialismo y la distancia u oposición a Estados Unidos, ya que ambas regiones han sido afectadas por intervenciones de Washington (por ejemplo, América Latina durante la Guerra Fría y Medio Oriente durante parte de la Guerra Fría y luego a partir de la invasión de Irak en 2003).

El proceso de diversificación de las relaciones con países de Medio Oriente tuvo efectos negativos sobre la relación que los países suramericanos tenían con Israel debido a sus acciones sobre la población palestina y su estrecha alianza con Estados Unidos. Por tanto, la posición propalestina de estos países ha llevado a constantes condenas a Israel por sus acciones e incluso al quiebre de relaciones diplomáticas, como sucedió con Venezuela y Bolivia en 2009. En este sentido, Venezuela jugó un rol esencial en trasladar el conflicto palestino-israelí a la región a partir de su profundización de relaciones con países como Irán, que apoyan a Palestina y son contrarios a las políticas de Washington. Por consiguiente, la presencia que 
tuvo Irán en Latinoamérica ampliamente apoyada por Chávez y sus aliados a partir de 2005 contribuyó al clima hostil hacia la población judía dentro de los países de la región (Siegel, 2011). De esta forma, la trayectoria histórica e ideológica de América Latina basada en el antiamericanismo ${ }^{1}$, anticolonialismo y anti-imperialismo generó un vínculo con el antisemitismo, antisionismo y crítica hacia Israel (Bokser, 2011).

Teniendo en cuenta el contexto anterior, la emergencia del antisemitismo en Venezuela se encuentra asociada a las acciones realizadas por el Gobierno y no a un fenómeno de la sociedad venezolana, ya que su población se ha caracterizado por no tener altos índices de antisemitismo -30\% según el índice global de antisemitismo de la Liga Anti Difamación de 2014- y queda así por debajo de países como Chile $(37 \%)$, Uruguay $(33 \%)$, Perú (38\%) y Colombia $(41 \%)$ con porcentajes mayores al registrado por Venezuela (ver figura 1). No obstante, las primeras señales de antisemitismo en el Gobierno venezolano tienen su origen desde 2004, cuando se llevó a cabo la primera acción violenta hacia la comunidad judía con el allanamiento al colegio Hebraica, con la justificación de que allí había armas que se habrían usado en el asesinato del fiscal Danilo Anderson (Ascanio, 2012; Lomnitz y Sánchez, 2009). Posteriormente, en 2007 ocurre otro allanamiento a ese mismo colegio sin ninguna explicación (Ascanio, 2012). El colegio Hebraica es el punto focal de la vida comunitaria judía en el país, que alberga una escuela privada y se facilita como lugar para bodas y otras ceremonias religiosas, por lo que los ataques fueron vistos como una agresión a toda la comunidad judía (United States Commission on International Religious Freedom [USCIRF], 2009).

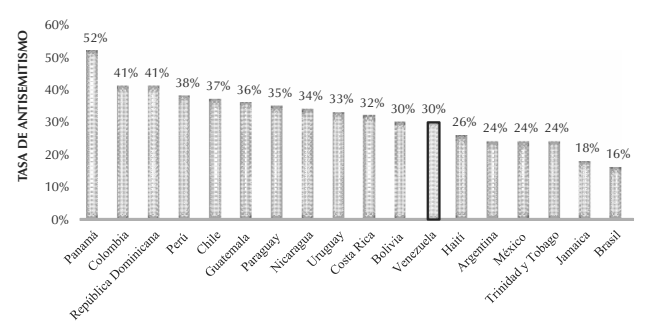

Figura 1. Índice de antisemitismo en América Latina (2013)

Fuente: elaboración propia, a partir de los datos del ADL Global 100 (2014).

Por otro lado, a nivel presidencial, es a partir de 2005 que comienzan a manifestarse públicamente expresiones antisemitas por parte de Hugo Chávez. Aquel año en su discurso de Navidad relacionó a los judíos con la apropiación de la riqueza mundial (Lomnitz y Sánchez, 2009). Posteriormente, en diversas declaraciones Chávez vinculó a los judíos con Israel y sus acciones en Palestina, así como con el "imperialismo norteamericano", maldiciendo abiertamente al pueblo judío y realizando comparaciones con los nazis por sus acciones hacia al pueblo palestino (Lomnitz y Sánchez, 2009; Grupo ReVista, 2010; Rivero, 2009). Igualmente, culpó a Israel de estar

Por antiamericanismo se entiende el rechazo hacia Estados Unidos. 
detrás de la oposición al Gobierno, sumado a las constantes acusaciones y declaraciones antisemitas hacia Henrique Capriles por su ascendencia judía durante las elecciones de 2012 (Lerner, 2012; Lomnitz y Sánchez, 2009). En enero de 2009, a raíz de la guerra del Líbano y el bombardeo de Israel en Gaza, la postura del Gobierno de Chávez se endurece y expulsa al embajador de Israel en Venezuela, Shlomo Cohen, además de romper relaciones diplomáticas con Israel en enero de ese mismo año (Ascanio, 2012; Boersner, 2009; El País, 2009; Rivero, 2009) y de registrar alrededor de 200 ataques contra la comunidad judía en el país durante 2009 (Grupo ReVista, 2010). Ese mismo año, la Uscirf, encargada de monitorear la defensa del derecho universal a la libertad de religión en el extranjero, incluyó a Venezuela en la lista de países "en observación", debido a los incidentes en los que se vieron practicadas expresiones y acciones antisemitas hacia la población judía del país (Uscirf, 2009).

Como consecuencia de lo anterior, el Gobierno de Chávez se convirtió en lo que se conoce como Governmentsponsored, referido a aquel Gobierno que patrocina el antisemitismo de varias formas incluyendo publicaciones gubernamentales, discursos de líderes, publicaciones en medios de comunicación controlados por el Gobierno, en leyes y prácticas discriminatorias, y cuando los Gobiernos no toman medidas eficaces para condenar o combatir el antisemitismo en su territorio (U.S. Department of State, 2008).
Por otro lado, los medios de comunicación como radio, televisión y prensa escrita son otros ámbitos donde se evidenció la emergencia de un antisemitismo. A nivel comunicacional, diversos medios oficiales y simpatizantes del Gobierno bolivariano -como Correo del Orinoco, Telesur o Cadena nacional radio- manifestaron públicamente su antisemitismo y a partir de 2009 estos se tornaron más agresivos en sus publicaciones, las que aumentaban en los momentos de mayor tensión del conflicto palestino-israelí y que en 2013 superaron las 100 publicaciones al año (ver tabla 1) (Lomnitz y Sánchez, 2009).

Tabla 1. Principales medios de comunicación de Venezuela que superaron las 100 publicaciones en 2013

\begin{tabular}{|c|c|c|}
\hline $\begin{array}{c}\text { Tipo de } \\
\text { medio de } \\
\text { comunicación }\end{array}$ & $\begin{array}{c}\text { Principales } \\
\text { medios }\end{array}$ & $\begin{array}{c}\text { Total } \\
\text { publicaciones }\end{array}$ \\
\hline \multirow{4}{*}{ Prensa escrita } & $\begin{array}{l}\text { Correo del } \\
\text { Orinoco }\end{array}$ & 412 \\
\hline & Diario Vea & 205 \\
\hline & Ciudad CCS & 172 \\
\hline & $\begin{array}{l}\text { Últimas } \\
\text { Noticias }\end{array}$ & 117 \\
\hline \multirow{3}{*}{ Televisión } & VTV & 441 \\
\hline & Telesur & 414 \\
\hline & $\begin{array}{l}\text { Cadena } \\
\text { Nacional / TV }\end{array}$ & 339 \\
\hline \multirow{4}{*}{ Radio } & $\begin{array}{l}\text { Cadena } \\
\text { Nacional / } \\
\text { radio }\end{array}$ & 2250 \\
\hline & $\begin{array}{l}\text { La Radio del } \\
\text { Sur }\end{array}$ & 205 \\
\hline & RNV & 185 \\
\hline & Yvke Mundial & 143 \\
\hline
\end{tabular}

Fuente: elaboración propia, a partir de los datos del informe de Antisemitismo en Venezuela 2013 (Confederación de Asociaciones Israelitas de Venezuela, 2013). 
La Confederación de Asociaciones Israelitas de Venezuela (CAIV) en su informe de 2013 sobre antisemitismo en el país, señala que los medios oficiales siguieron estando al frente de la difusión de los mensajes antisemitas $\left(72,4 \%\right.$ con la cadena ${ }^{2}$ y $54,5 \%$ sin cadena), seguido por los alineados a la ideología gubernamental (12,2\% con la cadena y $20,1 \%$ sin cadena), los que prácticamente coparon el universo estudiado (ver figuras 2 y 3) (CAIV, 2014).

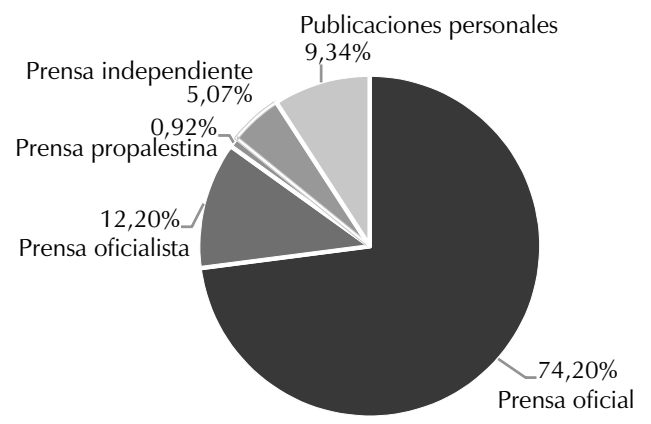

Figura 2. Publicaciones antisemitas según la línea editorial (con cadena)

Fuente: elaboración propia, a partir de los datos del informe de Antisemitismo en Venezuela 2013 (CAIV, 2013).

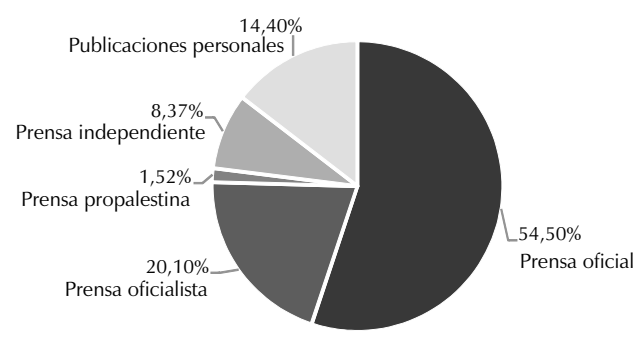

Figura 3. Publicaciones antisemitas según la línea editorial (sin cadena)

Fuente: elaboración propia, a partir de los datos del informe de Antisemitismo en Venezuela 2013 (CAIV, 2013).
Como consecuencia del hostigamiento, además de la situación económica y la violencia en el país, se produjo una emigración de judíos venezolanos (DellaPergola, 2013, p. 50; Shefler, 2010; Uscirf, 2009). En 1999 había un total de 22.000 judíos en el país, cifra que cae en el año 2000 con un total de 18.000 miembros (Uscirf, 2013). Mientras que en 2013 quedaban solo unos 9000, sumado al número de judíos venezolanos que migraron hacia Israel (110), uno de los más altos registrados en el país entre 2011 y 2012 (DellaPergola, 2013). Igualmente, el alcance de los ataques contra la comunidad judía provocó una crítica sin precedentes por parte de la Comisión Interamericana de Derechos Humanos (CIDH) de la Organización de Estados Americanos (OEA) (Widder, 2011). La CIDH manifestó su preocupación a raíz de los distintos incidentes y ataques hacia la comunidad judía y solicitó información al Estado sobre los acontecimientos acaecidos en la escuela Hebraica; no obstante, la Corte consideró insuficiente la información dada para aclarar las circunstancias suscitadas en la sede de esa institución (Widder, 2011).

Por consiguiente, en los diversos análisis acerca de la emergencia del antisemitismo en el Gobierno surgen diferentes explicaciones sobre su origen. Algunos autores recalcan el rol que tuvo el sociólogo y neonazi ar-

Con cadena se refiere aquel medio cuyo emisor o fuente es el Ministerio del Poder Popular para la

Comunicación e Información. 
gentino Noberto Ceresole en la configuración del pensamiento antisemita en el bolivarianismo, quien planteaba un revisionismo mediante posiciones antijudías y antiisraelíes, y negaba así el Holocausto e igualaba a los israelíes con los nazis (Roniger, 2009), a quien Chávez defendió de críticas remarcando la importante amistad que sostenían y citándolo en ocasiones como fuente de inspiración (Boersner, 2009; Lomnitz y Sánchez, 2009). Sin embargo, si bien el pensamiento antisemita en el bolivarianismo estuvo presente desde sus inicios (Roniger, 2009), es a partir de 2009 con los bombardeos en Gaza por parte de Israel y la guerra en el Líbano que Chávez y sus adeptos comienzan a expresar y hostigar públicamente al pueblo judío, y terminan con el accionar diplomático e imparcial de Venezuela frente al conflicto palestino-israelí y lo convierte en una de las fuentes que propició el antisemitismo en el Gobierno (ADL, 2009, 2010; Boesner, 2009; Caro, 2015; Siegel, 2011).

Sin embargo, gran parte de la literatura reconoce que fue la profundización de las relaciones con Irán bajo el mandato de Mahmud Ahmadineyad (20052013) lo que reforzó los sentimientos y expresiones antisemitas por parte del presidente venezolano, el Gobierno y sus simpatizantes (ADL, 2010; Ascanio, 2012; CAIV, 2012; CAIV, 2014; Grupo ReVista, 2010; Rivero, 2009; Roniger, 2009; Siegel, 2011; Uscirf, 2011, 2012). Chávez construyó lazos con Irán, pasando de la membresía compartida en la Organización de Países Expor- tadores de Petróleo (OPEP) a diversos proyectos de cooperación económica y relaciones internacionales; defendió el derecho de Irán a desarrollar la energía nuclear; declaró a Venezuela e Irán como "hermanos que luchan por un mundo justo" y negoció con estos una serie de acuerdos económicos (Roniger, 2009). A partir de la profundización de dicha relación, el presidente venezolano fue más vociferante contra Israel, lo que generó olas de sentimiento antijudío, algo inédito en el pasado de Venezuela (Roniger, 2009).

De esta manera, y dado el rol de Irán en la emergencia y aumento del antisemitismo en los Gobiernos de Chávez, ¿cómo se explica la relación entre el aumento del antisemitismo en el Gobierno venezolano y la profundización de las relaciones de Venezuela con Irán entre 2005 y 2013? Para responder la pregunta de investigación, este artículo propone tres hipótesis.

\section{Hipótesis 1: naturaleza comercial de la relación}

En esta hipótesis se plantea que la profundización de las relaciones entre Venezuela e Irán desde 2005 y su relación con el aumento del antisemitismo se debieron a la firma de múltiples acuerdos y proyectos comerciales a partir de 2005. Desde ese año Irán emerge como principal socio comercial de Venezuela en Medio Oriente, donde la consolidación de relaciones permitiría, por un lado, hacer frente a la influencia e "imperialismo" de Estados Unidos y sus aliados en ambas 
regiones, y por otro, esquivar las políticas de aislamiento económico de Irán. Esta alianza comercial explicaría la importancia que adquirió el país persa para el Gobierno de Chávez y su influencia respecto a su relación con Israel como principal socio de Estados Unidos, lo que tuvo directa relación con el trato de Chávez y su Gobierno hacia la población judía venezolana.

\section{Hipótesis 2: naturaleza estratégica de la relación}

Esta hipótesis sostiene que la relación entre ambos fenómenos obedeció a la convergencia de objetivos internacionales comunes, como la búsqueda de la construcción de un mundo multipolar, el equilibrio planetario, el fortalecimiento de la cooperación sur-sur y el establecimiento de un polo de poder latinoamericano a nivel mundial. De esta forma, Irán contribuiría a los objetivos de Chávez sobre la construcción del orden multipolar, mientras que Caracas apoyaría a Teherán en sus decisiones y posturas internacionales, como el caso del conflicto palestinoisraelí del cual Venezuela tomó parte apoyando la causa palestina. Esto último explicaría el desarrollo del antisionismo en Chávez y su Gobierno, y generaría como consecuencia un antisemitismo en el este.

\section{Hipótesis 3: naturaleza ideológica de la relación}

Esta hipótesis plantea que la relación entre los dos fenómenos radica en el antiimperialismo como principio orientador y fundador del bolivarianismo y el Gobierno de Chávez. Expresado en su oposición a Estados Unidos, el antiimperialismo fue la base que fortaleció las relaciones con Irán. Al ser este el principal enemigo de Estados Unidos como de Israel, lo convirtió en un actor estratégico para que Venezuela pudiera hacer frente al "imperialismo estadounidense" y como consecuencia de ello, el Gobierno de Ahmadineyad transmitió el antisionismo al Gobierno de Chávez, lo cual tuvo efectos sobre el trato hacia la comunidad judía venezolana.

\section{Metodología de la investigación}

A partir de la pregunta e hipótesis de investigación antes mencionadas, el objetivo del artículo es explicar la relación entre la profundización de las relaciones de Irán y Venezuela de 2005 a 2013 y el aumento del antisemitismo en el Gobierno venezolano durante los últimos dos mandatos de Hugo Chávez. Específicamente, busca establecer la relación que existe entre el factor comercial, estratégico e ideológico, tras lo cual se determina que es este último factor el que explica la relación entre ambos fenómenos.

Para su realización se utilizaron fuentes primarias sobre comercio internacional y prensa, además de fuentes secundarias como artículos científicos e informes de organizaciones e instituciones que registran y analizan incidentes de antisemitismo en Venezuela, América Latina y a nivel mundial. Estas fuentes 
fueron analizadas mediante un análisis process tracing o seguimiento de procesos para poder establecer la existencia de relación causal entre la profundización de las relaciones entre Irán y Venezuela y el aumento del antisemitismo durante los Gobiernos de Hugo Chávez, por medio del descarte de hipótesis a partir de evidencia empírica.

Por último, la relevancia de la investigación reside, principalmente, en complementar los análisis sobre antisemitismo en América Latina, así como los temas de derechos humanos e intolerancia religiosa en el siglo XXI a partir del caso venezolano, el cual posee ciertas características que lo diferencian del antisemitismo tradicional desarrollado durante la Segunda Guerra Mundial y que lo insertan en la categoría de nuevo antisemitismo. Asimismo, este país tras la llegada de Hugo Chávez adquirió un protagonismo y una influencia a nivel regional e internacional, por lo que su análisis es relevante respecto a la importancia de la ideología bolivariana y su relación con el antisemitismo y antisionismo.

\section{Antisemitismo: definición y origen del concepto}

El término antisemitismo fue creado por Wilhelm Marr en 1879; sin embargo, León Pinsker señaló que el concepto más apropiado para referirse a la aversión hacia los judíos es la judeofobia, ya que permite señalar directamente al destinatario, el judío, y el sufijo "fobia" alude al carácter irracional del fenómeno (Caro, 2015; Perednik, 1999). A pesar de que este último concepto es el correcto, en este artículo se seguirá utilizando la palabra "antisemitismo" por razones prácticas, debido a que gran parte de los informes, análisis, instituciones académicas que reportan la hostilidad hacia los judíos y que serán usados en esta investigación siguen usando ese término.

De esta forma, la definición de antisemitismo más integradora es la realizada por el Observatorio Europeo del Racismo y Xenofobia (EUMC) en 2005, que agrupó intelectuales, representantes de gobierno e instituciones, quienes definieron el antisemitismo como:
Una determinada percepción de [hacia] los judíos que puede ex- presarse como odio hacia los ju- díos. Las manifestaciones retóricas y físicas de antisemitismo se dirigen tanto hacia individuos judíos o no judíos y/o sus bienes, hacia las ins- tituciones de la comunidad judía e instalaciones religiosas. (European Parliament Working Group On An- tisemitism, 2016, s. p.)

No obstante, el EUMC señala que las manifestaciones antisemitas también pueden tener como objeto al Estado de Israel, el que es concebido como una colectividad judía. El antisemitismo se expresa en discursos, escritos, formas visuales y acciones, en el empleo de estereotipos siniestros y rasgos de carácter negativos (European Parliament Working Group On Antisemitism, 2016). 
Algunos ejemplos contemporáneos de antisemitismo son:

- Ayudar o justificar el asesinato o el daño de los judíos en nombre de una ideología radical o una visión extremista de la religión.

- Hacer acusaciones falsas, demonizadas o estereotipadas sobre los judíos, como el poder de los judíos como colectividad, el mito de la conspiración judía a nivel mundial o el control de los judíos sobre los medios, la economía, el Gobierno u otras instituciones.

- Acusar a los judíos como responsables de la maldad real o imaginaria cometido por una persona judía o grupo de judíos o una persona no judía.

- Negar el Holocausto al pueblo judío durante la Segunda Guerra Mundial.

- Acusar a los judíos como pueblo o a Israel como Estado de inventar o exagerar el Holocausto.

- Acusar a los ciudadanos judíos de ser más leales a Israel o alegar prioridades de los judíos a nivel mundial y no sobre los intereses de sus naciones (European Parliament Working Group On Antisemitism, 2016).

\section{Nuevo antisemitismo}

El nuevo antisemitismo se diferencia del antisemitismo tradicional en el cual el elemento racial e individual (el judío) ya no se encuentra presente y es sustituido por aquellos elementos que hacen referencia al Estado de Israel, donde las acciones y sentimientos antisemitas se basan en argumentos religiosos, culturales o políticos, a menudo articulados en un lenguaje antiracista (Judaken, 2008).

El nuevo antisemitismo se origina en 1948 como consecuencia de la creación del Estado de Israel y su conflicto con los países árabes y Palestina. Sin embargo, es después de la Guerra de los Seis Días de 1967 cuando emergen las primeras publicaciones y escritos que mencionan el surgimiento de un nuevo antisemitismo ${ }^{3}$ (Judaken, 2008). Comúnmente se manifiesta en la forma de oposición al sionismo y la existencia del Estado o las políticas de Israel (U.S. Department of State, 2008). De acuerdo con EUMC (European Parliament Working Group On Antisemitism, 2016), las manifestaciones de antisemitismo en referencia a Israel ${ }^{4}$ son:

- Negar al pueblo judío su derecho a la autodeterminación.

- Aplicar doble estándar en exigir cierta conducta a Israel que no se pediría a otro Estado.

- Usar símbolos e imágenes asociados al antisemitismo clásico para caracterizar a los israelíes.

3 Por ejemplo, las publicaciones de Jacques Givet "La Gauche contre Israël? Essai sur le néo-antisémitisme" en 1968, Foster y Epstein "The New Anti-Semitism" en 1974 y Shmuel Ettinger "Le Caractére de I'antisémitisme contemporain" en 1975.

$4 \quad$ Las críticas hacia el Estado de Israel no se consideran antisemitas cuando estas son similares a las que se realizan a otros Estados. 
- Comparar las políticas de Israel con los nazis.

- Responsabilizar colectivamente a los judíos por las acciones del Estado de Israel.

Las diferentes definiciones de nuevo antisemitismo tienen en común tres elementos. El primero es que el Estado de Israel o sionismo ha reemplazado al "judío" como objeto de aversión, por lo que los judíos no son apuntados como individuos, sino como un pueblo o nación y, por tanto, la crítica desproporcionada u odio hacia Israel es sufrida por los judíos como comunidad (Judaken, 2008). El segundo destaca el elemento político, donde el nuevo antisemitismo es asociado con una "nueva izquierda" o una "izquierda más radical", en el que Israel es representado como un poder colonialista con ambiciones imperialistas, asociadas además a su estrecha alianza con Estados Unidos (Judaken, 2008; Peace, 2009). El antisionismo comenzó a internalizarse en el pensamiento de izquierda durante la Guerra Fría y a partir de las luchas por la descolonización, lo que se agravó como consencuencia de la lucha por la liberación nacional de Palestina, la cual reemplazó a los movimientos de liberación nacional de los años 50 y 70 como el frente central en la lucha contra las desigualdades del orden neocolonial (Judaken, 2008).

El antisionismo, además, está asociado a un vociferante sentimiento antiestadounidense (o antiamericanista). La convergencia entre antisionismo y antiamericanismo tuvo su apogeo durante los gobiernos de George W. Bush y Ariel Sharon, en el que el unilateralismo de ambos países, sumado al mutuo apoyo, generó la emergencia de expresiones y sentimientos antisemitas (Judaken, 2008).

En el tercer elemento se encuentra el antisemitismo islamista, el cual refiere a la representación que ciertos grupos musulmanes más extremistas como Al Qaeda tienen sobre Israel y hacen de este elemento un factor central de su accionar. Esta imagen se caracteriza por mostrar a Tel Aviv/Jerusalem como una abstracción diabólica y como un país agresor, usurpador, pecador, ocupante, corruptor, infiel, asesino, bárbaro donde sus ciudadanos son vistos como parte fundamental de esta "fuerza oscura" (Judaken, 2008). Esta representación de Israel es transmitida a través de los espacios donde estos grupos interactúan. Por ejemplo, en Europa, estas representaciones se difunden en sermones en mezquitas y se comparten en grabaciones cinematográficas, televisión, Internet, periódicos y revistas, y a través de graffitis en las paredes de algunos centros islámicos de ciudades europeas (Judaken, 2008).

A partir de lo anterior, se ha abierto el debate respecto a si el antisionismo es antisemitismo. Para algunos, la igualdad entre ambos términos sirve como herramienta política para silenciar a aquellos detractores y críticos de Israel, mientras que para otros el antisionismo sí es antisemitismo porque niega la posibilidad del pueblo judío 
a la autodeterminación (Caro, 2015; Peace, 2009). Por consiguiente, la forma más conocida para distinguir entre la crítica hacia Israel y el antisionismo como antisemitismo es a través del "3-D test" de Natan Sharansky, donde el doble estándar hacia Israel, la deslegitimación y demonización de Israel contienen un núcleo antisemita (Judaken, 2008).

El doble estándar hacia Israel refiere a la aplicación de estándares normativos y críticos más exigentes hacia este país a diferencia de otros Estados. La deslegitimación se basa en que Israel es visto como producto de la neocolonización en Medio Oriente y, por tanto, no debiese existir, sumado a la negación del derecho a judíos a la autodeterminación nacional al mismo tiempo que le es permitida a otros grupos. Por último, la demonización de Israel se representa, principalmente, en la figura de Israel como un Estado racial, manifestado en la equiparación de este con los nazis y en la banalización, instrumentalización o negación del Holocausto (Judaken, 2008).

\section{Las relaciones entre Irán y Venezuela (2000-2013)}

Las relaciones entre Venezuela e Irán se remontan a la década de 1940 y bajo el marco de cooperación petrolera en la OPEP en los setenta. Sin embargo, el acercamiento entre ambos Estados se produce en 2000 con la visita del presidente Mohamed Jatami a Caracas como resultado de la cum- bre de la OPEP ese mismo año (Kourliandsky, 2013; Brun, 2008). A partir de ese momento, Chávez declaró su apoyo al país persa con el fin de "preparar el camino para la paz, la justicia, la estabilidad y el progreso para el siglo XXI" (Al-Manar, 2014, s. p.). Desde entonces, Venezuela firmó una serie de acuerdos de cooperación en materia de petróleo, petroquímica e industria, y alcanzó un total de 49 acuerdos (Diario Exterior, 2005; Web/AJS, 2005)

Posteriormente, tras la llegada de Mahmud Ahmadineyad a la Presidencia en 2005 Venezuela procuró profundizar los lazos con el país islámico. El presidente venezolano visualizó en Ahmadineyad (a quién ya conocía un año antes como alcalde de Teherán) un aliado que compartía sus mismos propósitos al coincidir sobre la definición de lo que debería ser la política exterior de los países en desarrollo, al tener una oposición total hacia los Estados Unidos y al apelar a un orden multipolar al igual que él (Brun, 2008), manifestando su promesa de estar al lado de Irán en cualquier momento y tiempo, y bajo cualquier circunstancia, ya que solo unidos podrían derrotar el imperialismo de los Estados Unidos (Al-Manar, 2014).

A partir de ese momento, las relaciones entre ambos países se basaron en el mutuo apoyo sobre las posturas internacionales tomadas por cada país, reflejado principalmente en el apoyo dado por Caracas al desarrollo del programa nuclear iraní, iniciativa ampliamente rechazada por Naciones Unidas 
y varios países del sistema internacional (Colmenares, 2011a). Cabe mencionar también la realización de múltiples visitas presidenciales. Chávez realizó 13 visitas a Teherán desde su llegada al poder hasta el 2013, mientras que Ahmadineyad visitó seis veces Caracas entre el 2005 y 2013, a lo que se suma la firma de más de 270 acuerdos en áreas de petróleo, petroquímica, tecnología y defensa (Botta, 2010; Hardy, 2008).

Esta profundización y alianza entre ambos Estados se vio concretada con el ingreso de Irán como país observador de la Alianza Bolivariana para los Pueblos de nuestra América (ALBA) en 2007, lo que permitió una mayor presencia y acercamiento del país islámico en la región latinoamericana y, en especial, con los países miembros del ALBA como Bolivia, Ecuador y Nicaragua (Caro y Rodríguez, 2009). En ese sentido, el petróleo fue esencial para la profundización de las relaciones entre ambos países. Los altos precios del crudo beneficiaron a estos países que supieron obtener provecho económico y político; con base en esto, se pudieron financiar la cooperación bilateral y las triangulaciones, así como también ayudas e inversiones de Irán y Venezuela a otros países, como por ejemplo Bolivia que firmó diversos memorándum de entendimiento para fomentar diversas áreas de desarrollo industrial y energético (Moreno, 2010).

De este modo, el acercamiento con Bolivia, Ecuador y Nicaragua, gracias a la influencia de Chávez sobre los presidentes Evo Morales (Bolivia), Ra- fael Correa (Ecuador) y Daniel Ortega (Nicaragua), le permitió a Irán acceder a nuevos socios estratégicos en la región con el objetivo de, por un lado, respaldar el desarrollo de su programa nuclear frente a las críticas y sanciones de Naciones Unidas al comprometer a estos países a promover el desarrollo pacífico de energía nuclear a través de diversos acuerdos de cooperación y, por otro lado, para evadir las sanciones económicas impuestas por Estados Unidos y países de Europa, y conseguir las materias primas que Irán necesitaba (Arnson, Esfandiari y Stubits, 2011).

La oposición al imperialismo, neoliberalismo, la globalización y la búsqueda de un mundo multipolar fueron los principales elementos que unieron a ambos países política e ideológicamente, y esto permitió una convergencia en cuanto a ciertos objetivos y acciones internacionales (Gratius y Fürtig, 2009). A partir de esta convergencia, los presidentes Ahmadineyad y Chávez adoptaron una estrategia agresiva en contra de Estados Unidos y líderes políticos de los países vecinos hostiles a sus revoluciones, teniendo como enemigo común a Israel (Gratius y Fürtig, 2009).

En definitiva, Irán y Venezuela se comprometieron profundamente a "[...] consolidar una alianza bilateral basada en la hostilidad compartida contra Estados Unidos y con Israel, uno de sus principales socios, así como en el interés de socavar la influencia de los estadounidenses en el Medio Oriente y en América Latina" (Colmenares, 2011a, p. 3). 
Durante el mandato de Mahmud Ahmadineyad en Irán (2005-2013) se produjo una profundización de las relaciones entre ambos países, que implicó la firma de diversos acuerdos de cooperación e inversión, visitas presidenciales entre ambos mandatarios y el ingreso de la República Islámica a la Alianza a Bolivariana para los Pueblos de Nuestra América (ALBA) como país observador en 2007. Esto permitió al país persa tener una mayor presencia y cercanía con la región latinoamericana, en especial con los países miembros de la organización (por ejemplo, Cuba, Bolivia, Ecuador y Nicaragua), con los que también estableció alianzas y políticas de cooperación (Botta, 2010; Caro y Rodríguez, 2009).

\section{La emergencia y el aumento del antisemitismo en los Gobiernos de Hugo Chávez y su relación con la profundización de las relaciones entre Venezuela e Irán (2005-2013): análisis y principales resultados}

\section{Hipótesis económica}

Desde el inicio del acercamiento de las relaciones entre Venezuela e Irán y su consiguiente profundización a partir de 2005, se planteó la importancia del interés económico que sustentó la relación, ya que esta permitiría hacer frente a la influencia y al "imperialismo" de los Estados Unidos (Colmenares, 2011a; Hardy, 2008; Moreno, 2010).

Con la llegada de Ahmadineyad a la Presidencia iraní las relaciones entre ambos países se dinamizaron y consolidaron. A partir del "intento de generar un polo de poder internacional opuesto a Washington y, a la vez, para demostrar que ambos regímenes tenían socios extra regionales, es que se intentó establecer una cooperación bilateral que incluyera la mayor cantidad posible de áreas" (Botta, 2010, p. 138). Durante el periodo 2005-2013 se firmaron más de 270 acuerdos y proyectos que incluyeron "la construcción de fábricas de tractores y automóviles en Venezuela y también colaboración en los campos de la ciencia y de las medicinas, así como la participación de empresarios iraníes en los transportes, el sector agrícola y el alojamiento" (Brun, 2008 , p. 27). De estos acuerdos y proyectos destacan la instalación de una fábrica de tractores nombrada como Veniran Tractor; el contrato entre la empresa estatal venezolana Minerven y su par iraní Impasco, que otorgó a esta última la concesión de una mina de oro; la instalación de una fábrica de cemento en el Estado Monagas, cuya construcción fue ejecutada por la firma iraní Edhasse Sanat, y la conformación de un joint venture entre Petróleos de Venezuela (PDVSA) y Petropars de Irán, para la certificación de las reservas de un bloque de la faja petrolífera del Orinoco (Colmenares, 2011a).

En el ámbito financiero se encuentra la creación de un banco binacional de desarrollo a partir de la alianza entre el estatal Banco Industrial de Venezuela y el Banco de Exportaciones y Desarrollo de Irán (EDBI) (Colmenares, 2011a). Por último, destaca la creación 
del vuelo entre Caracas y Teherán con escala en Damasco (las capitales de tres países que tienen una agenda política contraria a Estados Unidos) como resultado del acuerdo entre las aerolíneas Conviasa e Irán Air (Caro y Rodríguez, 2009; Colmenares, 2011a).

Así, la profundización entre ambas naciones se caracterizó por la multiplicidad de acuerdos, convenios y proyectos firmados durante los ocho años de consolidación de las relaciones. Sin embargo, a pesar de los cientos de tratados firmados por Venezuela solo hubo 31 acuerdos refrendados y publicados en Gaceta Oficial en 2009 (Botia, 2009). Por otro lado, muchos de los llamados convenios no pasaron de ser simples memorandos de entendimiento o actas de intención, además, algunos de los acuerdos formales nunca se concretaron o se dilataron indefinidamente (Botia, 2009).

Asimismo, mediante un análisis de los intercambios comerciales, las exportaciones de Venezuela a Irán representaron menos del $1 \%$ del total de exportaciones venezolanas y en periodos de mejor relacionamiento comercial Irán logró obtener en año 2006 el puesto 46 de los mercados más importantes para las exportaciones venezolanas (UN Comtrade data, 2016). Mientras las importaciones desde Irán solo lograron representar el $0,2 \%$ de las importaciones totales de Caracas y en los momentos de mayor prosperidad en el comercio Irán obtuvo el puesto 39 de los mercados más importantes para las importaciones ve- nezolanas; esto ocurrió durante 2008 y 2009 (UN Comtrade data, 2016).

Por otro lado, desde Irán las exportaciones a Venezuela solo lograron representar el $0,1 \%$ del total de exportaciones iraníes al mundo, y en los años de mejor relacionamiento comercial Caracas obtuvo en 2006 el puesto 38 de los mercados más importantes para las exportaciones iraníes (UN Comtrade data, 2016). En cuanto a las importaciones desde Venezuela, estas representaron un porcentaje similar a las exportaciones, obteniendo en su mejor momento (año 2006) el puesto 33 de los mercados más importantes de las importaciones persas (UN Comtrade data, 2016).

En resumen, con base en la figura 4 se logra inferir que en el caso venezolano existe una mayor importancia de las importaciones desde Irán frente a las exportaciones (UN Comtrade data, 2016). Además, estas relaciones comerciales se han caracterizado por su inestabilidad, y se han logrado así crecimientos y disminuciones precipitadas de un año a otro, lo cual no logra dar cuenta de las profundas y consolidadas relaciones que ambos mandatarios manifestaron a lo largo de los ocho años de relacionamiento. Más aún, según datos de la Asociación Latinoamericana de Integración (ALADI) el comercio venezolano-iraní entre 2008 y 2009 fue alrededor de 81 y 79 millones de dólares respectivamente. En ese mismo periodo el comercio israelívenezolano fue de 40 y 46 millones de dólares aproximadamente, por lo 
que pese al quiebre de las relaciones diplomáticas entre Caracas y Tel Aviv/ Jerusalén en enero de 2009, a lo largo de ese año la relación comercial con
Israel experimentó un aumento; además, se destaca en algunos años un intercambio mayor al desarrollado con Irán (ver tabla 2).

Tabla 2. Comercio total de Venezuela (en miles de dólares americanos)

\begin{tabular}{|l|c|c|c|c|c|c|c|c|c|}
\hline \multicolumn{1}{|c|}{ País } & $\mathbf{2 0 0 5}$ & $\mathbf{2 0 0 6}$ & $\mathbf{2 0 0 7}$ & $\mathbf{2 0 0 8}$ & $\mathbf{2 0 0 9}$ & $\mathbf{2 0 1 0}$ & $\mathbf{2 0 1 1}$ & $\mathbf{2 0 1 2}$ & $\mathbf{2 0 1 3}$ \\
\hline Irán & 15.532 & 50.682 & 53.225 & 81.592 & 79.091 & 18.276 & 54.542 & 65.309 & 19.080 \\
\hline Israel & 45.420 & 24.353 & 52.205 & 40.227 & 45.857 & 25.166 & 25.108 & 34.536 & 23.189 \\
\hline
\end{tabular}

Fuente: elaboración propia, a partir de los datos de International Trade Map (2016).

Se debe señalar además que Estados Unidos desde 1999 hasta 2013 fue el primer socio comercial, tanto para las exportaciones, como para las importaciones venezolanas, lo que da cuenta de un accionar pragmático respecto a su relacionamiento comercial con Washington e Israel, los principales enemigos de Venezuela y de Irán (UN Comtrade data, 2016). De esta forma, la retórica pública antiimperialista, antiestadounidense y antiisraelí en ambos países no afectó los intereses económicos con sus principales aliados Comerciales, ya que para Irán Venezuela era uno de los socios estratégicos más importantes en América Latina para conseguir sus objetivos políticos inter-

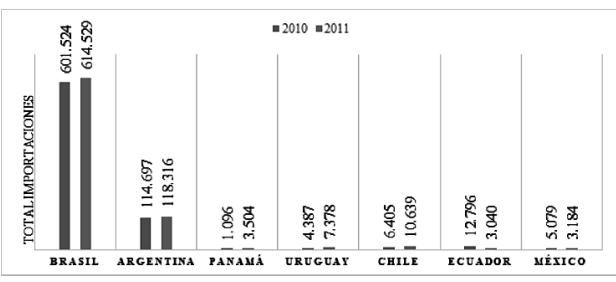

Figura 4. Total importaciones iraníes 2010-2011 (en miles de dólares americanos)

Fuente: elaboración propia, a partir de los datos de International Trade Map (2016). nacionales y, por tanto, lo comercial solamente complementaba la relación política que ambos desplegaban.

Lo anterior se ve demostrado en las relaciones comerciales que Irán desarrolló en la región, ya que sus principales socios comerciales no fueron los países del ALBA, sino las economías más importantes de la región latinoamericana (ver figuras 4 y 5), las que pudieron ofrecer a Irán los productos que necesitaba, particularmente productos primarios, en la cantidad y calidad deseadas (Botta, 2010). Esto explicaría por qué países como Brasil y Argentina, con quienes Irán no ha firmado tantos acuerdos, figuran como

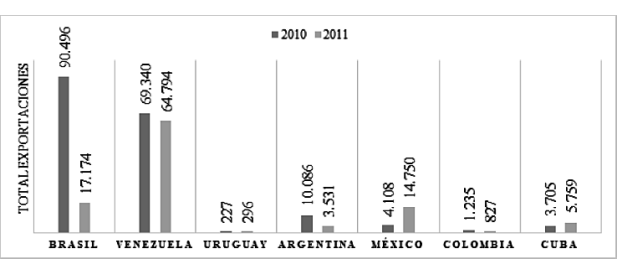

Figura 5. Total exportaciones iraníes 2010-2011 (en miles de dólares americanos)

Fuente: elaboración propia, a partir de los datos de International Trade Map (2016). 
aquellos países de la región donde existe mayor intercambio comercial, los cuales doblan la comercialización con Venezuela en cuanto a exportaciones (Kourliandsky, 2013). Empero, tanto la región como Venezuela se encuentran muy abajo en el ranking de los socios más importantes de Irán, por lo que América Latina no es una región estratégico comercial importante para el país persa, más bien es un espacio para conseguir commodities necesarios para su país (International Trade Centre, 2016).

En resumen, el contraste entre la multiplicidad de acuerdos y proyectos comerciales firmados entre ambos países que simbolizaron una alianza comercial y consolidación de las relaciones entre ambos países y la poca importancia del mercado iraní para Venezuela y viceversa en términos concretos, sumado a la poca cantidad de acuerdos y proyectos que se han logrado ejecutar, dan cuenta de que el peso de Irán como socio comercial de Venezuela es poco a pesar de los múltiples acuerdos firmados por ambos países. En consecuencia, la hipótesis que releva la importancia adquirida por Irán a partir de su fortalecimiento como socio comercial de Venezuela no logra ser comprobada empíricamente, ya que la relación comercial de ambos países da cuenta de un accionar pragmático y complementario, y no el pilar que fundamenta la profundización de la relación; además, no explicaría, por tanto, la influencia del país persa en Venezuela y su relación con el aumento del antisemitismo en el Gobierno de Chávez.

\section{Hipótesis estratégica}

La profundización de las relaciones del eje Caracas-Teherán desde esta hipótesis obedece a la convergencia frente a ciertos objetivos comunes, entre los que se encuentra el establecimiento de un mundo multipolar, la instauración de un orden internacional equilibrado sin un poder hegemonizado, el fortalecimiento de la cooperación sur-sur y la instalación de América Latina como una zona de influencia a nivel mundial (Colmenares, 2011a, 2011b; Moreno, 2010). A partir de ello, ambos países buscaron posiciones comunes en el escenario internacional, frente a políticas de Estados Unidos y los conflictos en Medio Oriente, con un accionar claramente motivado por el rechazo a los Estados Unidos (Moreno, 2010).

De esta forma, Irán se beneficiaría de su acercamiento con Venezuela, al permitirle tener una presencia en el hemisferio occidental y en especial en el "patio trasero" de Washington, lo que desafiaría directamente la hegemonía de los Estados unidos en la región latinoamericana y en Medio Oriente (Colmenares, 2011a). Asimismo, Teherán se benefició con el apoyo dado por Venezuela al desarrollo de su programa nuclear y la oportunidad dada por este último para superar su aislamiento político y económico en Medio Oriente debido a las sanciones económicas que Estados Unidos y Europa le aplicaron por su programa nuclear (Colmenares, 2011a; Moreno, 2010). De esta manera, la consolidación de las relaciones fue una forma de responder a 
las acciones de Estados Unidos en Medio Oriente y el aislamiento que este produjo a través del establecimiento de bases militares en sus países aliados de la región (Moreno, 2010).

Por otro lado, Venezuela se beneficiaría de esta profundización, ya que Irán le permitió llevar a cabo uno de los principales objetivos de su política exterior: el establecimiento de un orden multipolar. Así, con Irán Caracas logró fortalecer su protagonismo e influencia en la región latinoamericana, y de esta manera desafió a Washington con su principal enemigo a nivel mundial (Moreno, 2010).

Por lo tanto, esta profundización de las relaciones obedece a lo que diferentes autores realistas denominan una estrategia de equilibrio de poder, ya que mediante la alianza de mutua conveniencia entre ambos países, estos lograrían impedir la preponderancia de un Estado en particular (Estados Unidos) y mantener un equilibrio aproximado entre los principales rivales (por ejemplo, Israel) (Barbé, 1987). Aquello se manifestó en apoyo de Venezuela a Irán y Palestina en su conflicto con Israel; este último fue asumido como uno de los principales enemigos por ser el aliado más importante de Estados Unidos en Medio Oriente y a nivel mundial. A partir de ello, Venezuela estableció una alianza política con Irán que le permitió a este expandir en América Latina sus redes con grupos extremistas, donde el Gobierno de Chávez accedió al establecimiento de bases del Hezbollah en la Isla Margarita. De esto se destaca, además, la estrecha relación entre en chiísmo y la tribu wayuu de Venezuela (Schvindlerman, 2011). De igual forma, en 2010 Chávez se reunió con los líderes de Hamas, Hezbollah y la Palestina Yihad Islámica en centro de inteligencia militar venezolano de Caracas, donde nombró a Tarek El-Aissami de Hezbollah a cargo de la agencia venezolana de pasaportes, Ministro de Justicia e Interior y vicecanciller. El padre de El-Aissami además elogió públicamente a Sadam Hussein y Osama Bin Laden (Colmenares, 2011b; Schvindlerman, 2011).

En consecuencia, aquel escenario estratégico explicaría -en parte- la relación que Chávez y su Gobierno comenzaría a tener con Israel y que tuvo repercusiones directas sobre el trato a la comunidad judía venezolana. Sin embargo, esta explicación no logra evidenciar la razón por la cual prosperó y se consolidó tal relación, ya que bajo el Plan Estratégico 2007-2013 de Venezuela se establecía el fortalecimiento de las relaciones con Siria e Irán en Medio Oriente, pues ambos países son contrarios a Washington, son los principales enemigos de Israel y ambos son parte del islam chíta, por lo que uno y otro se presentan como aliados importantes para promover este orden multipolar y hacer frente al imperialismo estadounidense. Por tanto, ¿̇cuál es la razón por la cual prosperó y se profundizó la relación con Irán y no así con Siria, a pesar de que ambos presentan las mismas características geoestratégicas para Venezuela? Ante ello, el 
rol de la ideología en la consolidación de las relaciones es el elemento que explica la profundización de las relaciones y el aumento del antisemitismo en el Gobierno venezolano a partir de la influencia que Irán logra obtener en el país. Por tanto, se debe rechazar la hipótesis estratégica debido a su incapacidad para responder a tal pregunta.

\section{Hipótesis ideológica}

Teniendo en cuenta esta última hipótesis, la profundización de las relaciones entre Irán y Venezuela y su relación con el aumento del antisemitismo reside en el elemento antimperialista que comparten ambas revoluciones. El antiimperialismo es personificado en la figura de Estados Unidos a nivel mundial, que mediante sus aliados en diferentes regiones -como Israel en Medio Oriente- busca expandir su influencia y dominio alrededor del mundo.

Entre principios que rigen la política exterior iraní se encuentra la designación de los Estados Unidos como principal enemigo del país; la lucha contra las súper potencias y el poder sionista; el apoyo a los pueblos oprimidos en todo el mundo (especialmente los musulmanes); la liberación de Jerusalén, y el antiimperialismo (Moreno, 2010). Aquellos principios son compartidos por el bolivarianismo del Gobierno de Hugo Chávez, donde el antiimperialismo, es el principal elemento que guio su política exterior.

El antiimperialismo como elemento central del pensamiento de Hugo
Chávez y el bolivarianismo nace del profundo rechazo generado por el accionar de los diversos programas neoliberales nacidos del Consenso de Washington y aplicados en el país y la región latinoamericana a partir de los años 80 (Kozel, Grossi y Moroni, 2015). Esta concepción resalta los efectos negativos del orden económico desigual y expoliador, el enjuiciamiento de la tentativa de Estados Unidos por establecer una "dictadura imperial" en el planeta y el resurgimiento "de la conciencia del sur", es decir, el inicio de un nuevo ciclo político emancipador y liberacionista centrado en los pueblos de la periferia y de alcance global (Kozel, Grossi y Moroni, 2015).

En consecuencia, el bolivarianismo y la revolución iraní comparten ciertos principios, valores e ideas sobre la liberación de los pueblos oprimidos y el orden internacional. Esto lo explica el hecho de que Chávez y Ahmadineyad se hayan definido como "revolucionarios" y "hermanos", concibiendo ambas revoluciones como hermanadas y destinadas a acabar con el imperialismo estadounidense. Estos se comprometieron a apoyar a las "naciones revolucionarias" y "los frentes antiimperialistas" en el mundo, así como hacer sentir sus presencias globalmente para promover sus valores de independencia y justicia (Brun, 2008; Moreno, 2010; Siegel, s. f). Mediante la profundización de sus relaciones con Irán, Chávez buscó "difundir la ideología de su política, a fin de liderar un movimiento socialista, revolucionario y bolivariano, que traspase las fronteras 
latinoamericanas y que sea contrario a cualquier hegemonía estadounidense" (Moreno, 2010, p. 73).

De esta forma, el proyecto político y social antihegemónico de Hugo Chávez amparado en el principio antiestadounidense fue el que fundamentó y consolidó su relación con Irán frente a otros países como Siria. El bloque contrahegemónico venezolano-iraní no solo fue una alianza estratégica para hacer frente a Estados Unidos, sino que también era un conjunto de relaciones y prácticas duraderas sustentadas en una visión ética y política del orden internacional, como la justicia, igualdad y equidad internacionales (Burron, 2014; Hobden y Wyn, 2011).

Por otro lado, la definición ideológica de Irán como país geoestratégico para la profundización de las relaciones internacionales fue iniciada por la influencia de Noberto Ceresole sobre Chávez y el bolivarianismo (Widder, 2011). El fallecido sociólogo argentino, neofascista, antisemita y negador del Holocausto, fue íntimo amigo y asesor de Hugo Chávez desde el inicio de su carrera política hasta su muerte en 2003 (Roniger, 2009; Widder, 2011). Ceresole hizo contacto con Irán inmediatamente después del atentado a la Asociación Mutual Israelita Argentina (AMIA) en 1994 y culpó a los judíos y el servicio secreto israelí del incidente (Karmon, 2007). Visitó también el Líbano, donde conoció al Hezbollah y reconoció su importancia e inteligencia como movimiento (Karmon, 2007). Ceresole consideraba a Irán desde su revolución en 1979 como "el centro de la resistencia a la agresión judía" y el único Estado que ha suplantado a "la resistencia árabe secular" en la lucha contra el Estado judío (Karmon, 2007). Según él, a muchos les hubiese gustado ver la "contraestrategia" de Irán no solo en resistir la agresión israelí, sino también en destruir "cada pedazo de él", además, afirmó que la lucha contra Israel no podía ser circunscrita geográficamente solo a Medio Oriente (Karmon, 2007). De esta forma, Ceresole pudo transmitir las primeras ideas a Chávez sobre la importancia de profundizar las relaciones con Irán debido a su importancia en la lucha contra Israel en la región, ideas que posteriormente fueron reforzadas por la convergencia ideológica entre Ahmadineyad y Chávez, y los lineamientos de sus respectivos Gobiernos.

Por otra parte y relacionado con el elemento político y antisemitismo islamista que caracteriza el nuevo antisemitismo, existe una importante relación entre el discurso del islam radical y la extrema izquierda latinoamericana. Ambos movimientos políticos abogan por la liberación de las masas oprimidas alrededor del mundo y el establecimiento de una sociedad más justa y equitativa (Torres, 2006). Esto ha llevado al surgimiento de grupos islamistas latinoamericanos (como el Hezbollah de Venezuela), que combinan la lucha indígena y liberación nacional latinoamericana con los postulados del islam chií (Torres, 2006; Karmon, 2007; Widder, 2011). Para estos grupos, la lucha del islam es una 
lucha revolucionaria por la igualdad y liberación de los oprimidos, con lo cual existe una concordancia y continuidad entre el combate religioso (yihad) y la subversión liderada por los movimientos de izquierda radical (Torres, 2006). Si bien Hezbollah Venezuela reconoce no tener conexión con el Hezbollah libanés, ha expresado su apoyo a este último en su lucha contra Israel (Torres, 2006). Así, tanto Irán como Hezbollah luchan en Medio Oriente contra Tel Aviv/Jerusalén, lo que ha llevado a ambos actores a posiciones antisemitas frente a Israel y los judíos, con el fin de deslegitimarlo como Estado en la región y a nivel mundial, lo cual permite una transmisión de las representaciones negativas que estos grupos tienen sobre Israel hacia otros grupos simpatizantes de las luchas de liberación nacional en América Latina.

En resumen, la profundización de las relaciones entre Irán y Venezuela se halla en la convergencia ideológica que ambas revoluciones tienen respecto a la lucha contra el imperialismo personificado en Estados Unidos, la liberación de los oprimidos e igualdad a nivel global. A partir de ello, se genera una especie de ecuación entre Estados Unidos, Israel y el antiimperialismo, que consiste en que Israel como entidad judía y principal aliado de Washington a nivel mundial actúa como agente del "imperialismo" estadounidense en Medio Oriente, lo que explicaría su conflicto con los países árabes y en especial con Palestina. Así, Israel por medio del lobby judío en el Congreso de los Estados Unidos asegu- raría la dominación judía en la región y a nivel mundial.

En consecuencia, el respaldo de Chávez a países que combaten a Israel (por ejemplo, Irán y Palestina) implicaba el apoyo a la lucha contra el imperialismo estadunidense y los valores hegemónicos que este intentaba instaurar a través de Israel en Medio Oriente. Este apoyo derivó en una postura antisionista por parte del Gobierno venezolano con el fin de deslegitimar a Israel y al "imperialismo" estadounidense a nivel mundial. Sin embargo, esto tuvo efectos sobre el trato a la comunidad judía venezolana, la que fue responsabilizada por los actos de Israel en Palestina, así como acusada de ser agentes de Israel y desleales a Venezuela. De esta forma, el antisionismo desarrollado por el Gobierno de Chávez generó un contexto que permitió la emergencia y aumento de un antisemitismo en el Gobierno, situación que se vio reforzada por la profundización de relaciones con Irán.

Por consiguiente, todas las características antes señaladas son parte de los elementos que caracterizan al nuevo antisemitismo, al tener a Israel como objeto de aversión y al imperialismo, antisionismo y antiamericanismo como parte de los valores que unen a ambos países, y también la presencia de una posible transmisión del antisemitismo por parte de grupos islamistas de carácter extremista, como el caso de Hezbollah Venezuela. Además, el antisionismo como antisemitismo se ve verificado en el Gobierno de Chávez, 
al contener las "3-D". El doble estándar hacia Israel al condenarlo de forma más severa por crímenes y delitos en territorio palestino en comparación con otros países; la deslegitimación al romper relaciones diplomáticas en 2009, con lo que se desconoce su reconocimiento como Estado, y la demonización de Israel constatada en las declaraciones donde comparó a Israel con los nazis.

\section{Conclusiones}

El nuevo proyecto social del bolivarianismo planteó directrices fundamentadas en la lucha contra el imperialismo y el neoliberalismo. A nivel internacional, se estableció y promovió la construcción de un orden internacional multipolar, equitativo y justo que hiciera frente a las desigualdades y a la influencia e "imperialismo" de Estados Unidos. Para ello, la profundización de relaciones con países contrarios a las políticas de Washington en las diferentes regiones a nivel mundial era esencial para la consecución de tales objetivos. De esta forma, el Plan 20072013 estableció a Siria e Irán como países claves en Medio Oriente para lograr aquella multipolaridad y contrapeso a los Estados Unidos. No obstante, es con Irán con quien se logra un importante acercamiento y profundización de relaciones a partir de 2005, con la llegada de Mahmud Ahmadineyad a la Presidencia iraní. Este objetivo de la política exterior venezolana puede ser considerado exitoso en cuanto a que logró demostrar públicamente que ambos países tenían una importante alianza política y económica, mediante el apoyo mutuo y la firma de múltiples acuerdos de cooperación y proyectos.

Sin embargo, la relación comercial entre ambos países se caracterizó en la práctica por su carácter pragmático y complementario a la relación políticoestratégica que existía. Así, para Irán sus socios comerciales más importantes en la región fueron Argentina y Brasil, con quienes no firmó múltiples acuerdos, pero sí eran la fuente principal de materias primas que la República Islámica requería y que Venezuela no podía ofrecer. A lo anterior se suma el hecho de que varios de los acuerdos comerciales firmados por el eje Caracas-Teherán no alcanzaron su ejecución y quedaron simplemente en declaraciones de intención.

Por otro lado, Venezuela siguió manteniendo a Estados Unidos como su principal socio comercial mientras que con Israel, a pesar del quiebre de relaciones diplomáticas en 2009, logró en algunos años superar el comercio que Venezuela tuvo con Irán. En consecuencia, para la República Islámica la profundización de relaciones con Venezuela significó no solo la puerta de entrada hacia América Latina para respaldar su programa nuclear, evadir las sanciones económicas y desafiar a Estados Unidos en "su patio trasero", sino que también implicó en la práctica el desarrollo de una alianza con un socio ideológicamente similar con el que compartía diversos valores y visiones del orden internacional, y que por 
tanto aseguraría el apoyo irrestricto de él y sus aliados más cercanos hacia sus objetivos políticos internacionales. De esta manera, la consecución de los intereses políticos-estratégicos fue más importante que la consolidación de una fuerte relación comercial.

A partir de lo anterior, esta alianza político-estratégica, además de ideológica, se propuso ser la encargada de promover la justicia y equidad internacionales, al ser el eje visible de la contraposición a los Estados Unidos a nivel mundial y un reflejo de la cooperación y alianza entre países del "sur", misión que lograron demostrar públicamente en las diversas actividades diplomáticas bilaterales, triangulaciones con presidentes cercanos a Chávez y en la participación de Irán como miembro observador del ALBA.

Como consecuencia del desarrollo de una alianza político-ideológica, hubo una trasmisión de las enemistades políticas que Irán poseía en la región de Medio Oriente hacia la política exterior de Venezuela. De esta forma, Israel como principal enemigo de Irán y primordial aliado de Estados Unidos en la región, también se convirtió en el enemigo de Venezuela, lo cual se vio reflejado en la postura propalestina que adquirió la política exterior de Chávez frente al conflicto palestinoisraelí y que se fue endureciendo en la medida que fortalecía su relación con la República Islámica y su lucha contra el antiimperialismo. De esta forma, la radicalización de la postura hacia Israel hizo que las críticas hacia el Gobierno y sus acciones en Palestina se endurecieran y transitaran hacia el desarrollo un antisionismo y antisemitismo, el cual tuvo como objeto de crítica e insulto al Estado de Israel y la población de Venezuela.

En conclusión, la relación entre la emergencia y el aumento del antisemitismo durante los últimos dos Gobiernos de Hugo Chávez y la profundización de las relaciones entre Irán y Venezuela a partir de 2005 tienen su explicación en el factor ideológico, donde la convergencia ideológica sustentada en los valores de igualdad y justicia internacionales permitió la instauración de un bloque contra-hegemónico para enfrentar el "imperialismo" de Estados Unidos e Israel en el mundo. Por consiguiente, el apoyo incondicional de Venezuela al país persa en el conflicto palestino-israelí y el posterior desarrollo de un antisionismo tuvieron consecuencias directas sobre el trato de Chávez y su Gobierno hacia la comunidad judía venezolana, que además fue en diversas instancias responsabilizada por los actos del Gobierno de Israel hacia la población palestina. De este modo, al culpar a los judíos por las acciones de Israel en Palestina, Chávez, su Gobierno y simpatizantes del este incurrieron acciones y actitudes antisemitas, pasando desde el hostigamiento hasta la violencia física hacia personas de la comunidad judía del país. De esta forma, el caso venezolano representa un ejemplo en el que la fuerte crítica hacia Israel puede dar paso a un antisionismo, y por consiguiente, al desarrollo de un anti- 
semitismo que involucra ya no solo al Gobierno israelí, sino además al Estado de Israel y las comunidades judías. Por lo tanto, la emergencia y el aumento del antisemitismo en el Gobierno venezolano durante los mandatos de Hugo Chávez a partir del desarrollo de un antisionismo desde 2005 puede ser reconocido como un fenómeno de intolerancia religiosa en el siglo XXI.

\section{Referencias}

Al-Manar. (1 de enero de 2014). Irán y Venezuela: dos destinos cruzados. Recuperado de http://www.almanar.com.lb/spanish/adetails.php?fro $\underline{\text { mval }=2 \& \text { cid }=68 \& \text { frid }=26 \& \text { seccat }}$ $\mathrm{id}=68$ \&eid $=48860$

Anti-Defamation League (ADL) (2009). Chávez's Venezuela the jewish community under threat. Recuperado de http://archive.adl.org/ ia-0665chavezvenezuela\%20reportv6.pdf

Anti-Defamation League (ADL) (2010). Antisemitismo en Venezuela: tras el caso de la flotilla en Gaza. Recuperado de http://www.adl.org/assets/ pdf/international-affairs/2010-Espa-ol-ANTISEMITISMO-EN-VENEZUELA-TRAS-EL-CASO-DE-LAFLOTILLA-DE-GAZA.pdf

Anti-Defamation League (ADL) (2014). ADL global 100 an index of Antisemitism. Recuperado de http:// global100.adl.org/public/ADL-Global-100-Executive-Summary.pdf

Arnson, C., Esfandiari, H. y Stubits, A. (2011). Iran in Latin America:
Threat or "axis of annoyance". Woodrow Wilson International Center for Scholars. Recuperado de https://www.wilsoncenter.org/publication/iran-latin-america-threator-axis-annoyance-no-23

Asamblea General Naciones Unidas. (1991). Resolución 46/86. Eliminación racismo y la discriminación racial. Recuperado de http://www. cinu.org. mx/biblioteca/documentos/palestina/ares4686.pdf

Ascanio, R. (marzo, 2012). Antisemitismo en Venezuela. VenEconomía, 29(6). Recuperado de http://www. observatorio-arendt.org/wp/wpcontent/subidos/2014/10/Antisemitismo-en-Venezuela.pdf

Barbé, E. (1987). El equilibrio de poder en la teoría de las relaciones internacionales. Afers Internacionals, (11), 5-17. Recuperado de www. raco.cat/index.php/RevistaCIDOB/ article/download/27765/51884

Boersner, D. (2009). Israel, Palestina, Venezuela y el Pueblo Judío. Hora Internacional, 90-92. Recuperado de http://gumilla.org/biblioteca/ bases/biblo/texto/SIC2009712 9093.pdf

Bokser, J. (2011). México, en una región bajo cambio. Journal for Study of Antisemitism, 3(1). Recuperado de http://www.jsantisemitism.org/ images/journals/jsa_3-2.pdf

Botia, A. (4 de octubre de 2009). Hay 200 acurdos firmados, pero mucho no pasan del papel. Examen a laxos irán-Venezuela. El Tiempo. Recuperado de http://www.eltiem- 
po.com/archivo/documento/MAM3654575

Botta, P. (2010). Relaciones comerciales entre Irán y América Latina durante la presidencia de Mahmud Ahmadineyad (2005-2009). Relaciones Internacionales, 39, 129145. Recuperado de http://sedici. unlp.edu.ar/handle/10915/25888

Brun, E. (2008). Irán-Venezuela: hacia un acercamiento completo. Revista Politeia, 31(40), 19-40. Recuperado de http://www.redalyc.org/ $\underline{\mathrm{html} / 1700 / 170018396002 /}$

Burron, N. (2014). Counter-hegemony in Latin America? Understanding emerging multipolarity through gramscian lens. Revue Québécoise de Droit International, 33-68. Recuperado de http://www.sqdi. org/wp-content/uploads/RQDI HS201409 3 Burron.pdf

Caro, I. (2009). Fundamentalismos islámicos: conexiones sudamericanas, antisemitismo y rol de Irán en la región. Congreso Mundial de Ciencia Política (pp. 1-20). Santiago: IPSA. Recuperado de http://paperroom. ipsa.org/papers/paper_1554.pdf

Caro, I. (2015). Anti-semitism, antizionism and israeli-palestinian conflict from 2000 to 2014: some visions from latin american southern cone. Trames, 19(3), 289-307. Recuperado de http://www.kirj.ee/ public/trames_pdf/2015/issue_3/ trames-2015-3-289-307.pdf

Caro, I. y Rodríguez, I. (2009). La presencia de Irán en América Latina a través de su influencia en los países del ALBA. Atenea, (500), 21-39.
Cedeño, J. P. (2010). Diseño de la nueva política exterior venezolana: la incidencia de reformas institucionales (Tesis de maestría). Universidad Andina Simón Bolívar, Venezuela. Recuperado de http://repositorio.uasb.edu.ec/ bitstream/10644/2312/1/T0920MELA-Palatz-Dise\%C3\%B10\%20 de \%20la \%20 nueva \% 20 pol\%C3\%ADtica.pdf

Colmenares, L. (2011a). Las relaciones entre Irán y Venezuela: implicaciones para el gobierno venezolano. Programa de Cooperación en Seguridad Regional, 1-10. Recuperado de http://library.fes.de/pdf-files/ bueros/la-seguridad/08265.pdf

Colmenares, L. (2011b). Implicaciones estratégicas de las relaciones entre Irán y los Gobiernos izquierdistas de la ALBA. Military Review, 9-21. Recuperado de https://www. academia.edu/4101930/Implicaciones Estrat\%C3\%A9gicas de las Relaciones entre Ir\% $\overline{\mathrm{C}} 3 \% \overline{\mathrm{A}} 1 \mathrm{n}$ y los Gobiernos Izquierdistas de la_Á_BA

Confederación de Asociaciones Israelitas de Venezuela (CAIV) (2014). Antisemitismo en Venezuela informe 2013. Caracas: Confederación de Asociaciones Israelitas de Venezuela (CAIV). Recuperado de http:// www.caiv.org/antisemitismo/informe/informe2013.pdf

Confederación de Asociaciones Israelitas de Venezuela (CAIV) (2012). Antisemitismo en Venezuela informe 2011. Caracas: Confederación de Asociaciones Israelitas de Vene- 
zuela (CAIV). Recuperado de http:// www.caiv.org/medios/antisemitismo29032012.pdf

DellaPergola, S. (2013). World jewish population, 2013. Nueva York: Berman Jewish DataBank. Recuperado de http://www.jewishdatabank.org/studies/downloadFile. $\underline{\text { cfm? FilelD }=3113}$

Diario Exterior. (14 de marzo de 2005). El diario exterior. Recuperado de http://www.eldiarioexterior.com/elviaje-de-jatami-a-4008.htm

European Parliament Working Group On Antisemitism. (2016). Working definition of antisemitism. Recuperado de http://www.antisem.eu/ projects/eumc-working-definitionof-antisemitism/

El País. (15 de enero de 2009). Venezuela rompe relaciones diplomáticas con Israel. Caracas. Recuperado de https://elpais.com/ internacional/2009/01/15/actualidad/1231974007 850215.html

González, E. (2006). Las dos etapas de la política exterior de Chávez. Nueva Sociedad, (205), 159-171.

Gratius, S. y Fürtig, H. (2009). Iran and Venezuela: bilateral alliance and global power projections. Fundación para las Relaciones Internacionales y el Diálogo Exterior.. Recuperado de http://fride.org/ download/COM_Iran_Venezuela2_ENG_abril09.p̄df

Grupo ReVista. (2010). El Antisemitismo de Chávez. El $50 \%$ de la Comunidad Judía de Venezuela emigra en una década. ReVista de Medio
Oriente. Recuperado de http:// www.revistamo.org/article print. asp?articleID $=133$

Hardy, J. T. (2008). Las alianzas extraregionales en la política exterior de Venezuela. ILDIS. Recuperado de http://library.fes.de/pdf-files/bueros/caracas/05563.pdf

Hobden, S. y Wyn, R. (2011). Marxist theories of international relations. En J. Baylis, S. Smith y P. Owens (Eds..), The Globalization of World Politics: An Introduction to International Relations (pp. 225-247). Oxford: Oxford University Press.

International Trade Centre (ITC). (11 de junio de 2016). Trade Map. Recuperado de http://www.trademap. org/Index.aspx?lang=es

Judaken, J. (2008). So what's new? Rethinking the 'new antisemitism' in a global age. Patterns of Prejudice, 42(4-5), 533-560.

Karmon, E. (2007). International terror and antisemitism - two modern day curses: is there a connetion? ResearchGate. Recuperado de https://www.researchgate.net/ publication/265346766 INTERNATIONAL TERROR AND ANTISEMITISM - TWO MODERN DAY CURSES IS THERE A CONNECTION

Kourliandsky, J.-J. (2013). Irán y América Latina: más cerca por una conyuntura de futuro incierto. Nueva Sociedad, (246), 144-158.

Kozel, A., Grossi, F. y Moroni, D. (2015). El imaginario antiimperialista en América Latina. Buenos 
Aires: Centro Cultural de la Cooperación Floreal Gorini. Recuperado de http://biblioteca.clacso.edu.ar/ clacso/gt/20151021093846/imaginario.pdf

Krusch, D. (2013). Venezuela virtual jewish history tour. Recuperado de https://www.jewishvirtuallibrary. org/jsource/vjw/venezuela.html

Lerner, L. (2012). Antisemitism in venezuela's presidential election. Papers on Antisemitism and Racism. Recuperado de http://kantorcenter. tau.ac.il/sites/default/files/lidiafin 1.pdf

Linares, R. (2010). La estrategia multipolar de la política exterior venezolana. Aldea Mundo, 15(30), 51-62. Recuperado de http://www.redalyc. org/articulo.oa?id=54322875006

Lomnitz, C. y Sánchez, R. (2009). Antisemitismo bolivariano. Nexos. Recuperado de http://www.nexos. com.mx/?p=13241

Maihold, G. (2009). Foreign policy as provocation. Stiftung Wissenschaft und Politik, 5-32. Recuperado de https://www.swp-berlin.org/fileadmin/contents/products/research papers/2009_RP01_ilm_ks.pdf

Moreno, M. (2010). Irán en el actual escenario internacional: el ascenso de las relaciones con América Latina. Contra Relatos desde el Sur. Apuntes sobre Africa y Medio Oriente, 5(7). Recuperado de http://bibliotecavirtual.clacso.org.ar/Argentina/ceaunc/20110420093437/07-Moreno.p

Moya, S. (2011). Relaciones con Medio Oriente: inuevo eje estratégico de la política internacional latinoamericana? Relaciones Internacionales, 1(80), 1-19. Recuperado de http://www.wiphala.org/almedioriente.pdf

Organización de los Estados Americanos (OEA) (6 de mayo de 2013). Convención Interamericana contra toda forma de discriminación e intolerancia. Recuperado de http://www.oas. org/es/sla/ddi/tratados multilaterales interamericanos A-69 discriminacion intolerancia firmas.asp

Peace, T. (2009). Un antise'mitisme nouveau? The debate about a 'new antisemitism' in France. Patterns of Prejudice, 43(2), 103-121.

Perednik, G. (1999). Judeofobia. Panamá: Imprenta Universitaria.

República Bolivariana de Venezuela. (2007). Líneas generales del Plan de Desarrollo Económico y Social de la Nación 2007-2013. Recuperado de http://www.mppp.gob.ve/wpcontent/uploads/2013/09/Plan-dela-Naci\%C3\%B3n-2007-2013.pdf

Rivero, M. (12 de enero de 2009). Brotes de antisemitismo. Cuba Encuentro. Recuperado de http:// www.cubaencuentro.com/txt/internacional/articulos/brotes-de-antisemitismo-155292

Roniger, L. (2009). Venezuelan jews in the context of multiplicity of Latin American jewish experiencies. En L. Roniger, R. Wistrich y V. S. Antisemitism (Eds.), Antisemitism, real or imagined?: Chávez, Iran, Israel, and the Jews (pp. 2-36). Jerusalem: Hebrew University of Jerusalem, Vi- 
dal Sassoon International Center for the Study of Antisemitism.

Russell, R. y Tokatlian, J. (2009). Modelos de política exterior y opciones estratégicas. El caso de América Latina frente a Estados Unidos. Revista CIDOB d'Afers Internacionals, (85-86), 211-249. Recuperado de http://200.41.82.27/662/1/Russel\%20Roberto Modelos\%20 de $\% 20$ politica $\% 20$ exterior $\% 20$ y\%20opciones\%20estrategicas.pdf

Schvindlerman, J. (2011). América Latina y el Oriente Medio: el trasfondo político. Journal for the study of antisemitism, 3(2), 61-70. Recuperado de http://www.jsantisemitism. org/images/journals/jsa_3-2.pdf

Serbin, A. y Serbin Pont, A. (s.f). Quince años de política exterior bolivariana: ientre el soft-balancing y la militarización? Pensamiento Propio, 287-226. Recuperado de http://www.cries.org/wp-content/ uploads/2014/06/013-Serbin.pdf

Shefler, G. (01 de septiembre de 2010). Jewish community in Venezuela shrinks by half. The Jerusalem Post. Recuperado de http://www.jpost. com/Jewish-World/Jewish-News/ Lewish-community-in-Venezuelashrinks-by-half

Siegel, D. (2011). Antisemitism in Latin America: regional and Global Trends. Journal for the Study of Antisemitism (JSA), 3(2), 13-17. Recuperado de http://www.jsantisemitism.org/images/journals/jsa_3-2.pdf

Siegel, D. (s. f). Iran's presence in Latin America: Trade, energy, and ter- ror. American Jewish Committee. Recuperado de http://www.ajc.org/ atf/cf/\%7B42D75369-D582-43808395-D25925B85EAF\%7D/IranPresenceLatinAmerica_032007.pdf

Tel Aviv University. (2015). Antisemitism Worldwide 2015. Tel Aviv: Kantor Center. Recuperado de http:// www.kantorcenter.tau.ac.il/sites/ default/files/Report\%202015\%20 with\%20graphs.pdf

Torres, M. (2006). La fascinación por el éxito: el caso de Hezbollah en América Latina. Athenea Intelligence Journal, 1(1), 7-15. Recuperado de https://www.upo.es/ personal/mrtorsor/PUBLICACIONES/ANALISIS/op1.pdf

U.S. Department of State. (2008). Contemporary Global Anti-semitism A Report Provided to the United States Congress. Recuperado de http://www.state.gov/documents/ organization/102301.pdf

UN Comtrade data. (11 de junio de 2016). International Trade in Goods based on UN Comtrade data. Recuperado de http://comtrade.un.org/ labs/BIS-trade-in-goods/?reporter= 862\&partner $=364 \&$ year $=2011 \& \mathrm{fl}$ $\underline{\mathrm{ow}=2}$

United States Commission on International Religious Freedom (USCIRF) (2009). USCIRF Annual Report 2009 - The Commission's Watch List: Venezuela. Recuperado de http://www. refworld.org/docid/4a4f2729c.html

United States Commission on International Religious Freedom (USCIRF) (2011). USCIRF Annual 
Report 2011 - The Commission's Watch List: Venezuela. Recuperado, de http://www.refworld.org/ docid/4dbe90b52d.html

United States Commission on International Religious Freedom (USCIRF) (2012). Venezuela Chapter - 2012 Annual Report. Recuperado de http://www.uscirf.gov/sites/default/ files/resources/2012ARChapters/ venezuela $\% 202012 \% 20$ two $\% 20$ pager.pdf

United States Commission on International Religious Freedom (USCIRF) (2013). USCIRF 2013 Annual Re- port. Recuperado de http://www. uscirf.gov/sites/default/files/resources/Venezuela\%202013.pdf

Web/AJS. (30 de 11 de 2005). Radio Nacional de Venezuela. Recuperado de http://www.rnv.gov.ve/movil/ post.php?p $=44752$

Widder, S. (2011). América Latina y las redes del Terror Iraní: una tierra de oportunidades. Journal for the Study of Antisemitism (JSA), 3(2), 149-156. Recuperado de http:// www.jsantisemitism.org/images/ journals/jsa_3-2.pdf 